\title{
USE OF MONOLINGUAL, BILINGUAL, AND BILINGUALISED DICTIONARIES AND EFL LEARNERS' VOCABULARY LEARNING STRATEGIES: A CASE STUDY
}

\author{
Abdorreza Tahriri ${ }^{1}$ \\ Zeinab Ariyan ${ }^{2}$ \\ ${ }^{1}$ Department of English Language and Literature, University of Guilan, Rasht, Iran \\ ${ }^{2}$ Department of English Language, Payame Noor University (PNU), Tehran, Iran \\ 1atahriri@gmail.com \\ 2sghamgin277@yahoo.com
}

\begin{abstract}
This study investigated the effect of dictionary use on the vocabulary learning strategies used by elementary level EFL learners. Seventy-five female EFL learners were randomly assigned to one of three groups ( 25 members each): the monolingual dictionary, the bilingual dictionary, and the bilingualised dictionary groups. Students' responses on the vocabulary learning strategies were collected through a questionnaire which dealt with the vocabulary learning strategies the participants used to understand each target item in a reading passage selected based on readability formula. The results of Chi-square analysis indicated that the participants in the bilingual group consulted their dictionaries more frequently to solve their lexical problems than those in the monolingual and the bilingualised dictionary groups. The bilingualised group reported the least use of other strategies (e.g., analysing morphemes, and using cognates), while guessing was rarely reported by the bilingualised dictionary group. The results also revealed that the participants in the bilingualised and the bilingual dictionary groups were more willing to consult their dictionaries when reading the text than the monolingual dictionary group. In fact, guessing the meaning from the context as well as using other strategies was more common for the monolingual dictionary group.
\end{abstract}

Keywords: Type of dictionary, dictionary use, vocabulary learning strategies

\section{Introduction}

English is an international language and a good command of this language is essential to function in the world. As English teachers are unavailable outside the classroom, learners need to find a reliable source to refer to when they encounter a 
variety of problems related to English. Several studies (Cubillo, 2002; Ryu, 2006; Walz, 1990) identified dictionaries as a reliable source that provides learners with useful linguistic and cultural information, especially when teachers are unavailable and learners are responsible for their own learning. Huang (2003) considered dictionaries as useful, fairly common, and even necessary tools in language acquisition for EFL learners. It is an essential, if not the main source, of information on language for all literate individuals who have questions about the form, meaning, and the use of words in their first/second language (L1/L2) (Kirkness, 2004). A dictionary is a good educational tool for foreign language learners and it exists in different types: monolingual, bilingual or bilingualised. Baxter (1980), as well as Snell-Hornby (1987), suggest that their students use a monolingual dictionary. Atkins (1985) believes that learners prefer L2-L1 bilingual dictionaries because they satisfy their immediate needs. Laufer and Levitzcky-Aviad (2006) also emphasise the advantage of the bilingual dictionary.

Bilingualised (also called semi-bilingual dictionaries) are new developments. The bilingualised dictionary is a hybrid version in that it provides definitions and examples in L2 as presented in monolingual dictionaries and the equivalents in L1 as given in monolingual dictionaries (See Appendix A for a sample). Nakamoto (1995) stated that in these dictionaries, explanations in L2 are combined with L1 translation equivalents.

On the other hand, lexical competence covers a wide range of knowledge more than being able to define a word which in turn requires various strategies to achieve more complete knowledge. Foreign language learners may then use a variety of strategies to gain the target language word knowledge. According to Oxford (1990), learners take particular actions to make learning faster, more straightforward, more pleasurable, more self-directed, more efficient, and more transmissible to new situations, and these are called language learning strategies.

The present study was an investigation of the non-digital dictionary use and vocabulary learning strategies (VLSs) used by EFL learners at elementary level of proficiency - as measured by Oxford Placement Test (OPT) - to see how they cope with new vocabulary items in reading tests. The results of studies about the relationship between the type of dictionary preferred and used by students and their use of VLSs would be of great concern to both teacher trainers and language teachers. Inappropriate dictionaries and inappropriate use of dictionaries can be destructive to learners' language proficiency in EFL context since learners may overuse the dictionary. Any dictionary is a special kind of reference source that will require some learner training to be used effectively.

\section{Theoretical and Research Background}

Second language learners' acquisition of vocabulary has been discussed in numerous studies (e.g., Henriksen, 1999; Huckin \& Coady, 1999; Paribakht \& Wesche, 1999; Terrell, 1991) proposed the binding/access framework to illustrate the process of L2 learners' vocabulary acquisition. When $L 2$ learners encounter a vocabulary item in a given context, they have to match the word's meaning with the form first in order to understand the meaning of the vocabulary item. In addition, Henriksen (1999) 
proposed a three-dimensional model that is the partial-precise knowledge dimension, the depth of knowledge dimension, and the receptive-productive dimension for vocabulary acquisition. After the lexical network is built up, learners have to transfer the receptive items into productive ones. However, only a limited number of words that learners know receptively will become productive. Most lexical items initially enter the learners' receptive vocabulary knowledge, and may only subsequently become available for productive purpose. Moreover, some aspects of the learners' word knowledge may remain at the receptive level while some aspects become productive. Even though Henrickson's model indicates that vocabulary acquisition is a progressive continuum, another question arises: How does vocabulary acquisition happen? Paribakht and Wesche (1999) state that language learners' vocabulary acquisition takes place incidentally. This indicates that language learners' vocabulary learning is a by-product of other cognitive exercises that involve comprehension, such as listening, writing, and reading. However, there are also limitations of incidental vocabulary acquisition through reading. Guessing the meaning from context is imprecise, time-consuming, and it might slow down the reading process in some cases.

In what follows, major studies on various dictionary types (monolingual, bilingual, bilingualised types) will be reviewed. The description of meaning, characteristics of a word's grammatical behavior, and the illustration of meaning and the syntactic use of a word with real language examples are three features of EFL monolingual dictionaries as mentioned by Stein (1989). He suggests monolingual dictionaries for advanced learners. Similarly, monolingual dictionaries are preferred by Koren (1997) because bilingual dictionaries do not apply meaning discriminations of equivalent translation well. Atkins (1985, p. 22 as cited in Zarei, 2010), describes the differences between monolingual and bilingual dictionaries metaphorically: "monolinguals are good for you (like whole meal bread and green vegetables); bilinguals (like alcohol, sugar and fatty foods) are not, though you may like them better." On the other hand, he mentions a drawback of monolingual dictionaries, based on students' perspectives in their interviews, namely, they have to consult more new words to work out the meaning because English definitions in monolingual learners' dictionaries are not easy to understand.

Some scholars such as Atkins and Varantola (1997) and Baxter (1980) believe that bilingual dictionaries are popular among learners at all levels and research supports their use for both reading comprehension and vocabulary learning. Knight (1994) notes that lower proficiency learners show improved reading comprehension by using bilingual dictionaries whereas according to Hulstijn, Hollander, and Greidanus (1996), learners of all proficiency levels can utilize them in order to learn vocabulary. Scholars like Atkins and Varantola (1997), Hulstijn (1993) and Knight (1994) point out that less proficient learners tend to use bilingual dictionaries to look up completely unfamiliar words, while advanced learners are more likely to use them to confirm their understanding of slightly known L2 lexical items.

On the other hand, Baxter (1980) indicated one of the criticisms of bilingual dictionaries is that they may contribute to a narrow view of language learning as being only a matter of one-to-one word translation. Prince (1996) also stated that learners with poor language proficiency who rely on translation are less able to 
exactly transfer L1 information to L2 contexts. However, as Nation and Coady (2001) maintained, the issue here is not preventing the students from translation because learning $\mathrm{L} 1$ equivalents is a necessary and effective means for primary learning of new $L 2$ vocabulary.

The use of bilingual dictionaries while reading and their effect on vocabulary learning was also investigated by Luppescu and Day (1993). They found that except for some trade-offs, like reducing reading speed and confusing the learners, particularly when there are a lot of entries under the headword among which they should choose, students' use of bilingual dictionary might have a beneficial effect on their vocabulary learning.

Hayati and Pourmohammadi's (2005) study on the impact of bilingual and monolingual dictionaries on intermediate EFL students' reading comprehension showed no significant difference between the performance of students using bilingual dictionary and those who used the monolingual one.

Nakamoto (1995) pointed out that bilingualised dictionaries eliminate the learners' need to jump from the bilingual to the monolingual. Raudaskoski (2002) compared Finnish senior secondary school students' use of the bilingual dictionary and the bilingualised one, and discussed the superiority of these kinds of dictionaries. He concluded that despite all the translation errors caused by poor use of the bilingualised dictionary and its index, the bilingualised dictionary users had better performance than the bilingual dictionary users. He pointed out that efficient dictionary use requires some preliminary skills and healthy attitudes towards dictionaries.

According to Laufer and Hadar (1997), primary research shows that bilingualised dictionaries help to improve the comprehension of target vocabulary better than other types for all levels of learners although advanced learners may do nearly as well using monolingual learner dictionaries. A further advantage is that the options provided by bilingualised dictionaries allow learners to apply their preferred look-up style. A study by Laufer and Kimmel (1997) involving Israeli high school learners found a variety in students' use of L1 or L2 information depending on the word being consulted and in their look-up preferences. Some preferred bilingual information, others preferred monolingual one, and still others used both types.

Both bilingual and monolingual dictionaries have their strong points and weak points for developing vocabulary knowledge. As a result, there is considerable interest in the new bilingualised dictionaries, which is the consolidation of the two paradigms.

To sum up, from the scholars' points of view, it is possible to state that students' problems in learning a foreign language in general and vocabulary items in particular is not necessarily because of students' lack of appropriate VLSs but their inability to choose and use appropriate VLSs. Therefore, a good knowledge of VLSs and the ability to apply them in suitable situations might considerably simplify the learning of new vocabularies. 


\section{Purpose of study}

The following questions are addressed in the present study:

1. What vocabulary learning strategies do elementary EFL learners use to understand new vocabulary items in reading texts?

2. Is there any significant difference among the three experimental groups who are trained to use different types of dictionaries (monolingual, bilingual, and bilingualised) in terms of their vocabulary learning strategies?

The first research question is descriptive in nature. The following null hypothesis was formulated for the second research question:

$\mathrm{H}_{0}$ : There is no statistically significant difference among the three groups who use different types of dictionaries in terms of their vocabulary learning strategies.

\section{Method}

\section{Participants}

The participants were 75 randomly-selected female EFL learners studying in two language institutes at elementary level (defined as False Beginners in English) ranging from 12 to 20 years of age. The participants were randomly assigned to one of the three groups: the monolingual dictionary group, the bilingual dictionary group, and the bilingualised dictionary group, each consisting of 25 students.

The main criteria for the sample selection was their performance on OPT test. Based on the results of the OPT test, they were all at elementary level, scoring between 0 and 20 on the OPT test. None of the participants reported having contact with the target language seven or more hours per week.

\section{Instruments and Materials}

To accomplish the purpose of this study, four instruments and materials were used to collect the data.

Oxford Placement Test (OPT). This test, developed by Edwards (2007), was used as a pre-test to determine the proficiency level of the participants. The present study was concerned with the elementary level as a control variable. The only limitation of this test is that it does not apply to learners with proficiency levels higher than intermediate, but it can be a very useful test for elementary level participants. The cut-off score of 0-20 was set and 75 learners whose proficiency scores were within this range were selected as the main participants of the present study and were randomly divided into three groups (monolingual dictionary, bilingual dictionary, and bilingualised dictionary groups). 
Reading Test. A text appropriate for the participants' language level served as the reading passage. All selected target words were underlined in the text. It was adapted from an English website:

http://www.englishforeveryone.org/Topics/Reading-Comprehension.htm

The level of the test and the time needed for students to complete the reading were determined by using a readability formula.

Dictionaries. Three different types of dictionaries were used in this study: The monolingual dictionary, the bilingual dictionary and the bilingualised dictionary. The bilingualised dictionary is a hybrid dictionary (using both L1 and L2) which can conceivably bridge the gulf between the monolingual and the bilingual dictionaries. The three dictionaries available to the participants contained pages which defined the underlined words in the reading text.

Vocabulary Learning Strategy Questionnaire (VLSQ). The questionnaire (developed by Chin, 2001) contains several items regarding how the participants learn each selected vocabulary item. The learners were asked to indicate which strategy they used to learn the meaning of the new words by circling a number from 1) guessing from the context, 2) using a dictionary, 3) using other strategies (e. g., guessing, using dictionary, using cognates, etc.), to 4) learning the word beforehand. The questionnaire contains eight vocabulary items. The main idea was to test if the students who were trained to use three different types of dictionaries used these strategies and were familiar with them.

\section{Data Collection and Analysis Procedures}

Out of $160 \mathrm{EFL}$ learners who were studying English in two language institutes, 75 learners whose proficiency scores were within the range of 0 to 20 based on OPT manual were selected as the participants of the present study. They were randomly divided into three groups (monolingual, bilingual, and bilingualised groups).

As untrained users of dictionaries may encounter drawbacks such as unfamiliarity with the layout, unawareness of the phonemic script, and difficulty in getting the right meaning of a word according to the context, all participants were instructed on the functions of dictionary use in their respective groups for five sessions. They were taught the strategies for finding the entries and sub-entries. They also practised the changes of verbal tense, phonology, grammatical rules, collocation, word families, synonyms, antonyms, and any other information presented in the given dictionary.

The Vocabulary Learning Strategy Questionnaire (VLSQ) was translated into Persian in order to ensure the participants' understanding. Before administering the VLSQ, the reliability of the questionnaire was checked through running Cronbach's Alpha ( $r=0.723)$ in a pilot study with $15 \mathrm{EFL}$ learners comparable to the participants of the main study.

A reading text was given to the three groups on the same day and the participants were required to finish the reading within the required time which was determined through a readability formula. Next, the VLSQ was administered to 
investigate the participant' use of VLSs. The reliability of the VLSQ was also estimated for the researched groups through Cronbach's Alpha ( $r=0.775)$. The scores for the VLS items were analysed by computing the frequency, mean and standard deviation to identify the participants' preferred VLSs. This provided the answer to the first research question. For the second research question, Chi- Square was run in order to test the null hypothesis.

\section{Results}

As explained before, each group received instruction about dictionary use on the same terms with the help of the monolingual, bilingual, and bilingualised dictionary for five sessions. Afterwards, the participants were tested on eight terms and the specific VLSs used by each individual were examined and compared.

\section{Types of Vocabulary Learning Strategies Used by EFL Learners}

There were three types of learning strategies presented to the participants, namely, "guessing from the context", "using a dictionary" and "using other strategies" or alternately stating that they had "learned this word before". Table 1 shows that the vocabulary item "fortunately" seemed to be the easiest item for the learners since 24 participants reported that they had "learned its meaning before". On the other hand, the most difficult vocabulary item seemed to be "lean" which only 13 learners had learned before. Nearly 40 of the participants reported that they consulted their dictionaries for this word. The meanings of the words "flock" and "dependent" were guessed from the context by 32 participants. For the terms "assist" and "perform", 27 and 26 participants respectively claimed that they guessed the meanings from the context.

Table 1

Learning the meaning of the vocabulary item through guessing from the context

\begin{tabular}{lcccccc}
\hline $\begin{array}{l}\text { Vocabulary } \\
\text { item }\end{array}$ & $\begin{array}{c}\text { Bilingualised } \\
\text { dictionary } \\
(\mathbf{n = 2 5 )}\end{array}$ & \multicolumn{2}{c}{$\begin{array}{c}\text { Monolingual } \\
\text { dictionary } \\
(\mathbf{n = 2 5 )}\end{array}$} & $\begin{array}{c}\text { Bilingual } \\
\text { dictionary } \\
(\mathbf{n = 2 5 )}\end{array}$ \\
\cline { 2 - 8 } & $\mathbf{F}$ & $\mathbf{\%}$ & $\mathbf{F}$ & $\mathbf{\%}$ & $\mathbf{f}$ & $\mathbf{\%}$ \\
\hline Perform & 1 & 4 & 20 & 80 & 5 & 20 \\
Fortunately & 2 & 8 & 18 & 72 & 4 & 16 \\
Assist & 3 & 12 & 16 & 64 & 8 & 32 \\
Lean & 6 & 24 & 4 & 16 & 3 & 12 \\
Assignments & 1 & 4 & 17 & 68 & 6 & 24 \\
Tray & 1 & 4 & 15 & 60 & 9 & 36 \\
Dependent & 7 & 28 & 20 & 80 & 5 & 20 \\
Flock & 9 & 36 & 18 & 72 & 5 & 20 \\
\hline
\end{tabular}

In order to obtain deeper insights about how the VLS use differed among the groups, the strategies used by the participants in each group were analysed. To this 
end, the VLSs reported by the participants were analysed according to the type of dictionary that they used while reading the text (Table 1).

For the learners who received treatment in using bilingualised dictionaries, the vocabulary items "flock", and "dependent" were the easiest items, whose meaning were generated through guessing by 9 and 7 participants respectively (Table 1). About $80 \%$ of the participants in monolingual dictionary group reported that they learned these vocabulary items by guessing ( $80 \%$ for "perform" and $80 \%$ for "dependent"). In addition, the term "tray" was the less difficult item for the participants in bilingual dictionary group as just 36\% of the participants stated that they "found its meaning by guessing". Furthermore, the difficult vocabulary items for the bilingual dictionary group were "lean" (12\% determined this by guessing), and "fortunately" ( $16 \%$ also by guessing).

In general, the percentage of "using a dictionary" was apparently higher for the most difficult vocabulary item (lean) than the less difficult and the easier items (tray, perform, and fortunately). For instance, Table 2 shows that only four participants $(16 \%)$ in the bilingualised dictionary group and seven participants (28\%) in the monolingual dictionary group reported that they used the dictionary for the word "tray", but only one participant (4\%) in the monolingual group consulted the dictionary for "assist". Surprisingly none of the participants in the monolingual dictionary group reported the use of a dictionary for the words "perform" and "fortunately". This result indicated that the participants in the bilingualised dictionary and bilingual dictionary groups indeed were more eager to consult their dictionaries to solve their vocabulary problems while reading the text whereas the monolingual dictionary group was not so. Furthermore, in comparison to using a dictionary, guessing the meaning from context was more frequently used by the monolingual dictionary group, especially with the less difficult vocabulary items.

Table 2

Learning the meaning of the vocabulary item through using a dictionary

\begin{tabular}{lcccccc}
\hline $\begin{array}{l}\text { Vocabulary } \\
\text { item }\end{array}$ & $\begin{array}{c}\text { Bilingualised } \\
\text { dictionary } \\
(\mathbf{n = 2 5 )}\end{array}$ & \% & \multicolumn{2}{c}{$\begin{array}{c}\text { Monolingual } \\
\text { dictionary } \\
(\mathbf{n = 2 5 )}\end{array}$} & \multicolumn{2}{c}{$\begin{array}{c}\text { Bilingual } \\
\text { dictionary } \\
\text { (n=25) }\end{array}$} \\
\cline { 2 - 8 } & $\mathbf{F}$ & $\mathbf{F}$ & $\mathbf{\%}$ & $\mathbf{f}$ & \% \\
\hline Perform & 6 & 24 & 0 & 0 & 7 & 28 \\
Fortunately & 6 & 24 & 0 & 0 & 8 & 32 \\
Assist & 5 & 20 & 1 & 4 & 7 & 28 \\
Lean & 12 & 48 & 13 & 52 & 13 & 52 \\
Assignments & 6 & 24 & 2 & 8 & 11 & 44 \\
Tray & 4 & 16 & 7 & 28 & 5 & 20 \\
Dependent & 8 & 32 & 3 & 12 & 6 & 24 \\
Flock & 8 & 32 & 3 & 12 & 5 & 20 \\
\hline
\end{tabular}

In terms of "using other strategies" to find out the meaning of the words (Table 3), $24 \%$ of the learners in bilingualised dictionary group used other strategies for the words "assist" and "tray", 24\% of the monolingual dictionary group made use 
of other strategies for the words "lean" and "assignments" and $24 \%$ of the bilingual dictionary group used "other ways" to determine the meaning of "dependent".

Table 3

Learning the meaning of the vocabulary item through other strategies

\begin{tabular}{lcccccc}
\hline $\begin{array}{l}\text { Vocabulary } \\
\text { item }\end{array}$ & $\begin{array}{c}\text { Bilingualised } \\
\text { dictionary } \\
(\mathbf{n = 2 5 )}\end{array}$ & \multicolumn{2}{c}{$\begin{array}{c}\text { Monolingual } \\
\text { dictionary } \\
\text { (n=25) }\end{array}$} & $\begin{array}{c}\text { Bilingual } \\
\text { dictionary } \\
\text { (n=25) }\end{array}$ \\
\cline { 2 - 8 } & $\mathbf{F}$ & $\mathbf{\%}$ & $\mathbf{F}$ & $\mathbf{\%}$ & $\mathbf{f}$ & \% \\
\hline Perform & 3 & 12 & 2 & 8 & 5 & 20 \\
Fortunately & 4 & 16 & 2 & 8 & 3 & 12 \\
Assist & 6 & 24 & 2 & 8 & 3 & 12 \\
Lean & 4 & 16 & 6 & 24 & 1 & 4 \\
Assignments & 5 & 20 & 6 & 24 & 2 & 8 \\
Tray & 6 & 24 & 1 & 4 & 4 & 16 \\
Dependent & 3 & 12 & 1 & 4 & 6 & 24 \\
Flock & 3 & 12 & 1 & 4 & 4 & 16 \\
\hline
\end{tabular}

The data collected from the three groups in terms of "knowing the meaning of the words beforehand" indicated that when a bilingual dictionary was available to the elementary EFL learners, it was one of the most preferred sources that they used to solve their vocabulary problems. In addition, nearly the same number of participants in each of these three groups made use of learning strategies other than those mentioned in the questionnaire while reading the text.

As the results indicated, the participants in the three groups used a variety of strategies to understand the vocabulary items in the text and learn the meaning of the vocabulary items being tested.

\section{Relationship between Type of Dictionary Used and Vocabulary Learning Strategies}

Table 4 presents the frequency of each learning strategy used by the participants in different groups. The results show that the participants in the bilingual dictionary group $(n=62)$ and bilingualised dictionary group $(n=54)$ preferred using a dictionary more than other types of VLSs whereas the monolingual dictionary group preferred to guess the meaning from the context $(n=128)$. Among the three groups, the bilingual dictionary group was the most eager to use a dictionary to find out the meaning of the terms.

Moreover, the results of the analysis depicted that the participants had relatively different views towards using a specific type of learning strategy in the three groups. The participants in bilingualised dictionary group made the least use of "other strategies" $(n=17)$. On the other hand, use of "other strategies" was more common for the monolingual dictionary group $(n=35)$. 
Table 4

Frequency of learning strategies used by three dictionary groups

\begin{tabular}{lcccc}
\hline \multicolumn{1}{c}{ Learning strategy } & $\begin{array}{c}\text { Bilingualised } \\
\text { dictionary } \\
(\mathbf{n = 2 5})\end{array}$ & $\begin{array}{c}\text { Monolingual } \\
\text { dictionary } \\
(\mathbf{n = 2 5 )}\end{array}$ & $\begin{array}{c}\text { Bilingual } \\
\text { dictionary } \\
(\mathbf{n = 2 5 )}\end{array}$ & Total \\
\hline Guessing from the context & 30 & 128 & 45 & 203 \\
Using a dictionary & 54 & 27 & 62 & 143 \\
Other strategies & 17 & 35 & 28 & 80 \\
I had learned this word & 28 & 81 & 65 & 174 \\
before* & & & & \\
\hline
\end{tabular}

*This is not considered a strategy

In order to examine the second research question, a Chi-Square test was run to analyse the results of the vocabulary learning questionnaire for the three groups. The result of Chi-square analysis revealed that there is a significant relationship between the types of VLSs used by elementary EFL learners and the type of dictionary used (monolingual dictionary, bilingual dictionary, or bilingualised dictionary) $(p<.05)$ (see Table 5).

Table 5

Chi-Square Test

\begin{tabular}{ccc}
\hline & Value & Asymp. Sig. (2-sided) \\
\hline Pearson Chi-Square & $128.190^{\mathrm{a}}$ & .000 \\
\hline
\end{tabular}

To sum up, a significant relationship was found between the type of dictionary used and VLSs used, which means that the null hypothesis can be rejected; in fact, there is a significant relationship between the type of dictionary used and VLSs employed by elementary EFL learners.

Finally, the frequency of VLSs used by the three groups can be arranged in the following way: Guessed from context (203 times) > Used a dictionary (143 times) > Used other strategies (80 times).

\section{Discussion}

The findings suggested that there is a significant relationship between the type of dictionary and VLSs employed by EFL learners. These findings imply that elementary EFL learners' use of different dictionaries while reading contributed to their choice of different vocabulary learning strategies. Each type of dictionary helped EFL learners differently. Monolingual, bilingualised or bilingual dictionaries were restricted by both the type of information that they provided and, by the ways in which they represented this information.

The bilingual dictionary group consulted their dictionaries more frequently to solve their lexical problems than those in the monolingual and bilingualised dictionary groups. Unlike the bilingual dictionary group who could make use of their first language, the monolingual dictionary group could not make use of their native 
language when working with their dictionaries. As the study indicated, since learners in monolingual group often faced difficulties with the vocabularies and had problems in understanding the meaning of a particular word, they preferred to guess the meaning from the context rather than use a monolingual dictionary. This is because of the nature of a monolingual dictionary itself, which defines words solely in the foreign language. Elementary level students who had low levels of language proficiency certainly had difficulty in understanding these definitions in the foreign language, and this in turn affected their choice of VLSs.

Another reason that might have prevented the participants of the monolingual dictionary group from using a dictionary and encouraged them to use guessing or other strategies is that they did not consider it necessary to look up the meanings of most target words. This is in line with Hulstijn $(1997$, p. 335) who found that monolingual users mostly do not look up difficult words because they do not perceive them as relevant in the context of their reading comprehension. Hence, although they had access to a dictionary, they did not take full advantage of it.

On the other hand, the ease of using a bilingual dictionary was the major reason for the bilingual group to use a bilingual dictionary frequently when they had to look up the words in the reading passage. Bejoint and Moulin (1987; cited in Hayati \& Pourmohammadi, 2005) stated that bilingual dictionaries are ideal for quick consultation. Doing a comprehensive study including over 1000 learners in seven European countries, Bejoint and Moulin (1987) found that bilingual dictionaries were used by a majority of the students (75\%).

Instead of using their monolingual dictionaries, the participants in the monolingual dictionary group tried other ways to solve their vocabulary problems, while those in the bilingual dictionary group primarily relied on their bilingual dictionaries. One reason for these results could be that the participants in the monolingual dictionary group could not completely infer the given definition in the dictionary due to their lack of knowledge or understanding of the words used in the definition, while the bilingual dictionary provided the participants with Persian translation for each vocabulary item. Therefore, they did not consider the monolingual dictionary as their only source to solve lexical problems and they guessed meanings from the context. In fact, the participants in the bilingual dictionary group preferred to rely on definitions given in their bilingual dictionary, and not to bother to use other strategies such as guessing the meaning from context or using English cognates. This supports Baxter's (1980) and Atkins' (1985) ideas that bilingual dictionaries are not as demanding for language learners as monolingual ones. Instead of providing language learners with the alternative words and usage of target lexical items, bilingual dictionaries give them an instant translation of target items. Therefore, learners depend on their bilingual dictionaries more than on their monolingual dictionaries in the process of acquiring vocabulary in the target language.

In monolingual dictionary group, "using context to guess the meaning" of the words in the reading passage was reported 128 times. This strategy was reported only 30 times by the participants in the bilingualised dictionary group and 45 times by the bilingual dictionary group. This may also imply that monolingual dictionary users possess the competence to guess from the context by practicing the 
definition provided for them in monolingual dictionaries. The only disadvantage was that this took a lot of time, but the learners got used to it. Monolingual dictionaries are frequently used by advanced learners but in this study the one used for elementary users included a lot of information on grammar, usage, common errors, collocations, and so on.

\section{Conclusion}

These results revealed that the participants in the three groups had relatively different views towards using a specific type of learning strategy. Among the groups, the bilingual dictionary group was more eager to use a dictionary to find out the meaning of the terms and they used it more than other types of VLSs. The bilingualised dictionary group reported the least use of other strategies while guessing was rarely reported by the bilingualised dictionary group. The monolingual dictionary group also used their dictionaries less frequently than those in the bilingual dictionary group and tended to guess from the context.

The findings of this study revealed that elementary level learners of English have a variety of VLSs. Teachers' awareness of these strategies and different dictionaries along with their advantages and disadvantages can help them improve their teaching styles and choose more appropriate activities that can enhance their students' learning achievement. Thus, consulting a dictionary has the potential to be a productive strategy for $L 2$ learners to acquire new vocabulary. Nonetheless, we should remain cautious about sending our students rushing off to buy a monolingual dictionary and getting on alone with it. Consulting dictionaries is just one of several strategies available to our students for efficient and effective coping with unfamiliar words encountered during reading.

Since the consultation of dictionary has a positive impact on vocabulary learning and reading development, students should be encouraged to use dictionary in a consistent and appropriate manner. The distinction between different kinds of dictionaries should also be clarified for the students. By suggesting an appropriate dictionary type, teachers can help their students to improve their lexical proficiency as effectively as possible and enhance their vocabulary learning. Moreover, using suitable dictionary types, students will be able to learn new entries quickly. This also increases students' abilities in comprehension and production of unknown words, and makes them more efficient EFL learners.

In order to encourage students to use monolingual dictionaries, teaching dictionary skills should always be integrated with instruction and dictionary use training should be given priority in English class. To prepare students to learn how to use dictionaries, syllabus designers should provide exercises which demand that learners think about and use the word meanings learned from the dictionary. In conclusion, as educators, rather than thinking of consulting a dictionary as a reference skill only to be used as a last resort during reading tasks, we need to consider it as a lexical processing strategy which, if used appropriately and judiciously, has the potential to promote our EFL students' reading comprehension and vocabulary learning (Fraser, 1999). Loucky (2006, p. 363) also 
stated that "because of the proliferation of language-learning programs and websites, it becomes important to help define which most essential vocabulary and reading strategies should be included" in the programs.

\section{References}

Atkins, B. (1985). Monolingual and bilingual learners' dictionaries: A comparison. In R. Ilson (Ed.), Dictionaries, lexicography and language learning (pp. 25-42). Philadelphia: John Benjamin's Publishing Company.

Atkins, B. T. S., \& Varantola, K. (1997). Monitoring dictionary use. International Journal of Lexicography, 10(1), 1-45.

Baxter, J. (1980). The dictionary and vocabulary behavior: A single word or a handful? TESOL Quarterly, XIV(3), 325-336.

Chin, J. J. (2001). The effects of dictionary use on the vocabulary learning strategies used by language learners of Spanish. Paper presented at the Annual Meeting of the Acquisition of Spanish and Portuguese as First and Second Language. ED 471315

Cubillo, M. (2002). Dictionary use and dictionary needs of ESP students: An experimental approach. International Journal of Lexicography, 15(2), 206228.

Edwards, L. (2007). Placement test for Oxford: Solutions booklet. Oxford: Oxford University Press.

Fraser, C. (1999). The role of consulting a dictionary in reading and vocabulary learning. The Canadian Journal of Applied Linguistics 2(1-2), 73-89.

Hayati, A.M., \& Pourmohammadi, M. (2005). A comparative study of using bilingual and MLDs in reading comprehension of intermediate EFL students. The Reading Matrix: An International Online Journal, 5(2), 61-66.

Henriksen, B. (1999). Three dimensions of vocabulary development. Studies in Second Language Acquisition, 21, 303-317.

Huang, D. (2003). Taiwanese university English majors' belief about English dictionaries and their dictionary strategy use. Unpublished PhD Dissertation, University of Texas at Austin.

Hulstijn, J. (1997). Incidental vocabulary learning by advanced foreign language students. The Modern Language Journal, 79, 328-339.

Hulstijn, J. H., Hollander, M., \& Greidanus, T. (1996). Incidental vocabulary learning by advanced foreign language students: The influence of marginal glosses, dictionary use and reoccurrence of unknown words. Modern Language Journal, 80, 327-339.

Kirkness, A. (2004). Lexicography. In A. Davies \& C. Elder (Eds.), The handbook of applied linguistics (pp. 54-81). Oxford: Blackwell.

Knight, S. (1994). Dictionary use while reading: The effects on comprehension and vocabulary acquisition for students of different verbal abilities. The Modern Language Journal, 78(3), 285-299.

Koren, S. (1997). Quality versus convenience: Comparison of modern dictionaries from the teacher's and learner's points of view. TESL, 2, 1-16. 
Laufer, B., \& Hadar, L. (1997). Assessing the effectiveness of monolingual, bilingual, and "bilingualised" dictionaries in the comprehension and production of new words. The Modern Language Journal, 81(2), 189-196.

Laufer, B., \& Kimmel, M. (1997).Bilingualised dictionaries: How learners really use them. System, 25(3), 361-369.

Laufer, B., \& Levitzky-Aviad, T. (2006). Examining the effectiveness of "Bilingual Dictionary Plus": A dictionary for production in a foreign language. International Journal of Lexicography, 19(2), 135-155.

Loucky, J. P. (2006). Maximizing vocabulary development by systematically using a depth of lexical processing taxonomy, CALL resources, and effective strategies. CALICO Journal, 23(2), 363-399.

Luppescu, S., \& Day, R. R. (1993). Reading, dictionaries, and vocabulary learning. Language Learning, 43, 263-287.

Nakamoto, K. (1995). Monolingual or bilingual, that is not the question: The bilingualised dictionary. Kernerman Dictionary News, 2, 2-4.

Oxford, R. L. (1990). Language learning strategies: What every teacher should know. Boston: Newbury House.

Paribakht, T. S., \& Wesche, M. (1996).Enhancing vocabulary acquisition through reading: A hierarchy of text-related exercise types. The Canadian Modern Language Review, 52(2), 155-178.

Prince, P. (1996). Second language vocabulary learning: The role of context versus translations as a function of proficiency. The Modern Language Journal, 80 , 478-493.

Raudaskoski, S. (2002).Translation, the key or equivalent? A study of the dictionary use strategies of Finnish senior secondary school students. Kernerman Dictionary News, 10, 2-3.

Ryu, J. (2006). Dictionary use by Korean EFL college students. Language \& Information Society, 7, 83-114.

Snell-Hornby, M. (1987).Towards a learner's bilingual dictionary. In A. P. Cowie (Ed.), The dictionary and the language learner (pp. 159-170). Papers from the EURALEX Seminar at the University of Leeds, Tübingen: Niemeyer.

Stein, G. (1989). Recent developments in EFL dictionaries. In M. L. Tikoo (Ed.), Learner's dictionaries: State of the Art. Singapore. SEAMEO Regional Language Center.

Terrell, D. T. (1991). The role of grammar instruction in a communicative approach. Modern Language Journal, 75(1), 52-63.

Walz, J. (1990). The dictionary as a secondary source in language learning. The French Review, 64(1), 79-94.

Zarei, A. A. (2010). The effect of monolingual, bilingual and bilingualised dictionaries on vocabulary comprehension and production. ELT Weekly, 54, 17-40. 


\section{Appendix A: A Sample Entry in Various Dictionary Types}

- Longman Dictionary of Contemporary English (monolingual)

bequeath /bi'kwi: , bi'kwi: / $v\{T$ (to) $\}$ ml- to give to others after death: Her collection of paintings was bequeathed to the National Gallery when she died. $\{+o b j(i)+o b j(d)\}$ His father bequeathed him a fortune.

- The Megiddo Modern Dictionary (English-Hebrew)

bequeath vt horish, hinchil

- Oxford Student Dictionary for Hebrew Speakers (bilingualised)

bequeath 1 arrange (by making a will) to give (property, etc.) at death: He has bequeathed me his gold watch lehorish

2 hand down to those who come after: discoveries bequeathed to us by the scientists of the last century lehanchil 